\title{
Aproximación a la correspondencia como fuente para el estudio del clima: la necesidad de un análisis léxico
}

An approach to correspondence as a source for climate research: the need of a lexical analysis

Irene Andreu Candela

Universidad de Alicante

CESXVIII, núm. 29 (2019), págs. 13-36 DOI: https://doi.org/10.17811/cesxviii.29.2019.13-36

ISSN: 1131-9879

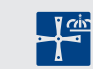




\section{Resumen}

Los epistolarios se han convertido en los últimos años en una de las diversas fuentes utilizadas en el estudio del clima del pasado, sin embargo, han sido pocos los estudios dedicados a este tipo de información a pesar del potencial que tienen. Este artículo pretende demostrar las posibilidades investigadoras de la correspondencia privada, en este caso la mantenida entre Carlos III y Bernardo Tanucci, comprobando en qué contexto aparecen estas referencias e incidiendo en la importancia de estudiar el lenguaje utilizado para describir los fenómenos meteorológicos.

Palabras clave

Correspondencia, clima, Pequeña Edad del Hielo, análisis de contenido, Carlos III.

\section{Abstract}

The correspondence has become in recent years one of the different sources used in climate research, however, few studies have been dedicated to this kind of information contained in the letters despite the potential they have. This article aims to demonstrate the investigative possibilities of private correspondence, in this case the one maintained between Carlos III and Bernardo Tanucci, checking in what context these references appear in the eighteenth-century epistolary exchanges, as well as stress the importance of studying the language used to describe meteorological phenomena.

KEY WoRDS

Correspondence, climate, Little Ice Age, content analysis, Carlos III.

Recibido: 4 de marzo de 2019. Aceptado: 18 de junio de 2019.

La autora de este trabajo cuenta actualmente con una Ayuda para la Formación del Profesorado Universitario del Ministerio de Educación Cultura y Deporte, con referencia FPU16/02637. 


\section{Introducción}

No es necesario reseñar la importancia de la correspondencia como fuente de conocimiento histórico, pues ha sido protagonista de muchos estudios desde diferentes perspectivas, como la investigación biográfica, la historia de las mentalidades y de la vida cotidiana, la historia política o la filología ${ }^{1}$. Nuestro objetivo no es incidir en su validez documental en estos ámbitos, sino en su papel como fuente climática. La información sobre los fenómenos meteorológicos es frecuente en la correspondencia pues, a causa del interés de los protagonistas por informar de las novedades más destacadas de la vida diaria a sus corresponsales, solían aparecer referencias a las condiciones atmosféricas cuando el tiempo mudaba o salía de lo esperable de la estación. Muchos investigadores se han percatado de la existencia de este tipo de referencias en las cartas, como Gimeno Puyol, quien, en su edición del epistolario del diplomático aragonés José Nicolás de Azara entre los años 1784 y 1804, destaca las palabras que solía dedicar a la meteorología, normalmente dando entrada a la carta en circunstancias excepcionales por su rareza o por lo deleitoso de ella²; también Antón Pelayo incide en la brevedad de las cartas que Giovanni Querini enviaba a su mujer, Caterina Contarini, quien se lamentaba porque el contenido de estas misivas se reducía a la meteorología, las aperturas económicas y su salud ${ }^{3}$; o Amor López, que advirtió la existencia de referencias climáticas en el epistolario de la familia Aparici, presentes sobre todo cuando las inclemencias del tiempo eran las culpables de que la llegada del correo se demorase o se perdiese ${ }^{4}$. Estas son

1 Un trabajo de referencia que analiza las posibilidades investigadoras de las misivas es el de Antonio Mestre Sanchís, «La carta, fuente de conocimiento histórico», Revista de historia moderna: Anales de la Universidad de Alicante, 18 (1999-2000), págs. 13-26.

2 José Nicolás de Azara, Epistolario (1784-1804), ed. de María Dolores Gimeno Puyol, Madrid, Castalia / Institución «Fernando el Católico», 2010, pág. CLIX.

3 Javier Antón Pelayo, «La práctica epistolar, pública y privada, de Giovanni Querini, embajador de la República de Venecia en España (1768-1773)», Cuadernos Dieciochistas, 14 (2013), págs. 261-282; pág. 274.

4 Silvia Amor López, «Las vías de análisis de la correspondencia: las cartas de los Aparici (siglo XVIII)», en Eliseo Serrano Martín (coord.), De la tierra al cielo: Líneas recientes de investigación en Historia Moderna, vol. 2, Zaragoza, Institución Fernando el Católico, 2013, págs. 1037-1054; pág. 1045. 
solo algunas menciones que evidencian que dedicarle al clima unas breves líneas en las cartas era una práctica frecuente a pesar de que nunca sean el tema central de este intercambio epistolar; y, sin embargo, los investigadores que indudablemente se habían percatado de la existencia de estas referencias por su recurrencia, no la habían convertido en el objeto de la investigación.

El creciente interés por la climatología histórica ha hecho que se indague en el patrimonio documental en busca de fuentes que proporcionen información sobre los fenómenos naturales o hidrometeorológicos. Entre muchas otras, la correspondencia forma parte de este corpus documental en el que consultar, pues la información climática encontrada en las cartas se puede convertir en el objeto de estudio de una investigación, tal y como han revelado recientes trabajos. Los resultados obtenidos por el profesor Alberola Romá a partir de los epistolarios de los ilustrados españoles durante la primera mitad del siglo XVIII ya demostraron el potencial que podía tener la correspondencia en el estudio de la historia del clima5; mientras que el profesor Mas Galvañ, con su investigación sobre el clima en la correspondencia de Carlos III con Felipe de Parma y Bernardo Tanucci entre 1759 y 1765 mostró la singularidad de la información climática que podían contener las misivas ${ }^{6}$. E, incluso, se ha usado este tipo de fuente para realizar reconstrucciones climáticas ${ }^{7}$. Actualmente, se están ampliando este tipo de estudios a nuevos epistolarios y conviene realizar un análisis previo que destaque en qué contexto suelen aparecer estas referencias climáticas, qué problemas puede plantear este tipo de fuente y cómo se pueden aportar soluciones a ellos.

\section{La información climática en la correspondencia}

En el momento presente, nos encontramos realizando una nueva aproximación a la información climática extraída de diferentes epistolarios, vaciando exhaustivamente aquellos que contenían más referencias. Aunque el trabajo

\footnotetext{
5 Armando Alberola Romá, «"No puedo sujetar la pluma de puro frío, porque son extremados los yelos": el clima en la España de los reinados de Felipe y Fernando VI a través de la correspondencia de algunos ilustrados», Investigaciones geográficas, 49 (2013), págs. 65-88.

6 Cayetano Mas Galvañ, «El clima en la correspondencia de Carlos III (1759-1765). Cartas a Felipe de Parma y Bernardo Tanucci», en Armando Alberola Romá (coord.), Clima, naturaleza y desastre: España e Hispanoamérica durante la Edad Moderna, Valencia, Universitat de Valencia Servei de Publicacions, 2013, págs. 17-54.

7 Fernando Sánchez Rodrigo, María Jesús Esteban-Parra y Yolanda Castrp-Díez, «On the use of Jesuit order private correspondence records in climate reconstructions: A case study from Castille (Spain) for 16341648 A.D.», Climatic Change, 40 3-4 (1998), págs. 625-645.
} 
aún no ha concluido, podemos acercarnos a las características de las referencias climáticas aportadas por este tipo de fuente a partir de las más de 3.000 cartas ya consultadas ${ }^{8}$. El periodo de estudio se concentra en el siglo XVIII, si bien algunos de los epistolarios se alargan hasta los primeros años del siglo XIX. En efecto, el uso de la carta como medio de comunicación fue aumentando a medida que avanzaba la Edad Moderna, cosa que se traduce en una mayor cantidad de documentación de este tipo en los archivos. Además, este criterio cronológico responde a la necesidad de conocer si existe relación entre estas referencias climáticas en la correspondencia y la aparición de las ideas ilustradas. En el Setecientos hubo un creciente interés por conocer el comportamiento de la atmósfera y su posible influencia en la vida humana, por lo que la variabilidad del tiempo se convirtió en un elemento de sociabilidad y en uno de los temas de conversación discutidos en tertulias y sociedades científicas ${ }^{9}$. Incluso, los debates sobre el clima y su influencia tienen su reflejo en la correspondencia, como se puede ver en la carta que Jovellanos envía a José Vargas Ponce, donde juzga — a petición de su corresponsal— su nueva obra titulada Discurso sobre la instrucción pública en la prosperidad del Estado. En ella, el ilustrado asturiano discute la posición de Vargas Ponce sobre esta cuestión ${ }^{10}$ :

Para probar que la instrucción y la prosperidad son independientes del clima y de la constitución, no era menester crear una opinión que no existe; pues ni Montesquieu atribuyó al clima un influjo absoluto, ni nadie que yo sepa se lo atribuyó antes ni después de él. Y menos era menester, tomando el extremo opuesto, quitar

\footnotetext{
8 La correspondencia utilizada para realizar este trabajo ha sido la siguiente:

Javier Antón Pelayo, La sociabilitat epistolar de la familia Burgués de Girona (1799-1803), Girona, Cercle d'Estudis Histórics i Socials de Girona, 2005.

José Nicolás de Azara, Epistolario (1784-1804).

Carlos III. Cartas a Tanucci (1759-1763), Introducción, transcripción y notas de Maximiliano Barrio, Madrid, Banco Bilbao Vizcaya, 1988.

Carlos III, correspondencia con Bernardo Tanucci (1763-1782), Archivo General de Simancas (AGS), Estado, libros 323 a 355.

Gaspar Melchor de Jovellanos, Obras, I: Epistolario, ed. de José Miguel Caso González, Barcelona, Textos Hispánicos Modernos Editorial Labor, 1970.

Gregorio Mayans y Siscar, Epistolario I. Mayans y los médicos, ed. de Antonio Mestre, Valencia, Publicaciones del Ayuntamiento de Oliva, 1972.

Gregorio MaYans y Siscar, Epistolario II. Mayans y Burriel, ed. de Antonio Mestre, Valencia, Publicaciones del Ayuntamiento de Oliva, 1972.

9 Armando Alberola Romá, «Tiempo, clima y enfermedad en la prensa española de la segunda mitad del siglo XVIII. Diarios meteorológicos y crónicas de desastres en el Memorial Literario», El Argonauta Español [en línea], 12 (2015), subido el 30 de enero de 2015, consultado el 19 de septiembre de 2018, http://journals. openedition.org/argonauta/2142; DOI: 10.4000/argonauta.2142.

10 En cada una de las citas literales que han sido utilizadas en este artículo se ha optado por actualizar las grafías para facilitar su comprensión.
} 
al clima todo influjo en la instrucción y en la prosperidad, cosa que ni es cierta ni se puede probar con ejemplos singulares ${ }^{11}$.

Estos debates, motivados por el aumento del interés en el clima por parte de los ilustrados ${ }^{12}$, podrían haberse traducido en una mayor atención por las condiciones climáticas diarias y su impacto directo en la sociedad, quedando así reflejadas en las misivas que enviaban a sus corresponsales más habituales. Sin embargo, no se ha podido establecer esta relación de manera evidente a partir del vaciado de los epistolarios consultados, por lo que es necesario seguir indagando en los fondos para poder validar o desechar esta hipótesis.

Se debe tener en cuenta que los registros climáticos instrumentales, es decir, aquellos realizados con termómetro y barómetro, no se fueron generalizando en Europa y también en España hasta finales del siglo XVIII ${ }^{13}$, de ahí la importancia de otros tipos de información que nos ayuden a conocer el funcionamiento del clima del pasado. Es por ello que las percepciones subjetivas contenidas en la documentación histórica se han convertido en una de las fuentes esenciales para este tipo de estudios, pero ha sido necesario establecer una serie de criterios que permitan que esta información sea válida ${ }^{14}$. Destacan las pautas establecidas por Pierre Alexandre, quien pone énfasis en la fiabilidad del documento y de la información que contiene, abogando por documentos originales que contengan descripciones de fenómenos experimentados por el emisor o al menos que sean contemporáneas a ellos ${ }^{15}$. En este sentido, los epistolarios son totalmente válidos, porque transmiten en primera persona información sobre su época y las circunstancias que lo rodean ${ }^{16}$.

También Le Roy Ladurie establece que para que la información obtenida en las fuentes sea apropiada debe ser perfectamente fechable, continua y cuantifi-

11 Carta de Jovellanos a José Vargas Ponce, Gijón, 11/12/1799; en Gaspar Melchor de JovelLanos, Obras I: Epistolario, pág. 123-124.

Las siguientes citas referentes a fragmentos de cartas omitirán este encabezamiento e indicarán directamente el remitente, el destinatario, el lugar en el que fue escrita y la fecha.

12 Armando Alberola Romá, Clima, crisis y reformismo agrario en tiempos del conde de Floridablanca», Mélanges de la Casa de Velázquez. Nouvelle série, 39-2 (2009), págs. 105-125.

13 Alberola Romá, «Tiempo, clima y enfermedad en la prensa española»

14 Mariano Barriendos I VALLVÉ, «Variabilidad climática y riesgos climáticos en perspectiva histórica el caso de Catalunya en los siglos XVIII y XIX», Revista de historia moderna: Anales de la Universidad de Alicante, 23 (2005), págs. 11-34, pág. 14.

15 Pierre Alexandre, Le climat en Europea au Moyen Âge, París, École des Hautes Études en Sciences Sociales, 1987.

16 Mercedes Abad Merino, «'Muy señor mío, dueño y amigo'. Lengua epistolar y élite social en la correspondencia privada del sureste español (1760-1805)», Tonos digital: Revista electrónica de estudios filológicos, [en línea], 30 (2016), págs.1-34, pág. 3, consultado el 20 de septiembre de 2018, URL: http://hdl. handle.net/10201/47871. 
cable $^{17}$. La correspondencia resuelve con éxito este primer criterio, pues es usual que en las misivas aparezca el día exacto y el lugar en que fue escrita. También el segundo, la continuidad, suele caracterizar a los epistolarios debido a que es frecuente que el carteo entre dos personas no sea un hecho aislado, sino un intercambio sostenido en el tiempo que crea un diálogo plasmado en el papel. Dentro del género epistolar, el tipo de cartas que más se adaptan a esta característica son las misivas privadas, que se han definido como aquellas que se intercambian entre particulares, excluyendo las cruzadas entre instituciones o entre estas y particulares ${ }^{18}$. El principal obstáculo en el estudio de la carta privada es que lo más común fue que no se guardaran, exceptuando algunos burgueses y nobles que las conservaron en sus archivos; es decir, que esta sociabilidad epistolar caracterizaba a las clases privilegiadas, pues los grupos populares no solían dirigirse a familiares o iguales, sino a instituciones o a poderosos ${ }^{19}$.

Los especialistas en la cultura escrita coinciden en que la función principal de la correspondencia privada es mantener los lazos de unión entre dos individuos separados, para lo cual se intercambiaba información tanto pública como personal, destacando las novedades de la vida del emisor, sus familiares y amigos o noticias de interés general. Así, una correspondencia privada sostenida en el tiempo reforzaba los lazos afectivos, que se autoalimentaban a través del intercambio de informaciones y noticias ${ }^{20}$. Es en este contexto en el que suelen aparecer un mayor número de referencias climáticas, es decir, en las cartas enviadas a los corresponsales con los que el intercambio epistolar es continuado. Ejemplo de ello es el epistolario publicado de José Nicolás de Azara, cuya recopilación está formada por 738 cartas enviadas a unos 50 corresponsales diferentes. Las más de 110 referencias climáticas encontradas solo se dirigen a ocho corresponsales y, de ellos, tres solamente reciben uno de estos comentarios. Es decir, que son cinco los corresponsales a los que Azara suele dedicar unas palabras sobre la meteorología reinante, que además coinciden con aquellos con los que tenía una relación epistolar más estrecha. Las misivas intercambiadas con ellos las podríamos catalogar como cartas privadas de carácter familiar, destacando las enviadas a Bernardo de Iriarte, con quien le unió una estrecha amistad. Por tanto, la continuidad de este intercambio epistolar con una misma persona facilita que exista información climática, aunque no la garantiza de manera continua. Como se ha comentado anteriormente, la tendencia general

17 Emmanuel Le Roy Ladurie, Historie du climat depuis l'an mil, París, Flammarion, 1983.

18 Silvia Amor López, La práctica epistolar a Catalunya (1700-1850): usos de la carta familiar, Tesis doctoral dirigida por Javier Antón Pelayo, Barcelona, Universitat Autònoma de Barcelona, 2015, pág. 191.

19 Antón Pelayo, La sociabilitat epistolar, pág. 16.

20 Amor López, La práctica epistolar a Catalunya, pág. 345. 
es que en las cartas se comunique aquello que se sale de lo habitual, es decir, que adquiere la categoría de extraordinario porque lo normal no trasciende a ser noticia ${ }^{21}$, de modo que la ausencia de referencias mientras los corresponsales sigan intercambiando misivas también se convierte en información en sí misma.

El último de los criterios anteriormente mencionados — la cuantificación de la información — es el más controvertido, pues estamos claramente ante una fuente subjetiva. La información meteorológica obtenida en la correspondencia se basa en meras percepciones personales del autor de la carta y de la manera en que el clima influía en sus actividades diarias o en la sociedad. Además, la heterogeneidad de los corresponsales es muy amplia, por tanto, tienen intereses personales distintos, al igual que diferente formación, cultura y posición social. Todas estas características influyen en la manera en que el observador refleja las percepciones meteorológicas ${ }^{22}$.

La vida cotidiana de los protagonistas de las misivas podía quedar interrumpida por las condiciones climáticas, como ocurre con el monarca Carlos III, quien suele quejarse del tiempo cuando le impedía salir a cazar. También podemos catalogar al propio intercambio epistolar como una de estas actividades habituales de los corresponsales, por lo que, si se interrumpía, era una noticia destacada en la propia correspondencia. Las lluvias y nieves intensas solían ser las principales responsables de que el correo se retrasara, tal y como Jovellanos relata en marzo de 1793: «Aquí no hay más novedad que la de estar cubiertos de nieve, cosa bien rara en esta costa. Hace diez días que no recibimos ningún correo y supongo que aún no están cerrados los puertos» ${ }^{23}$. Del mismo modo, era habitual que cuando el clima no era la causa de la interrupción del correo se notificase por resultar extraño: «No sé a qué atribuir el no haber aún llegado el correo de esta semana pues toda ha hecho aquí un tiempo hermosísimo» ${ }^{24}$. Igualmente, la meteorología podía impedir los desplazamientos, cosa que era notificada a los corresponsales y, en ocasiones, descrita minuciosamente:

Querido Bernardo: No te esperarás esta carta con esta fecha. Ayer a las dos llegamos a esta ciudad con intención de ir a dormir a Villacastín, pero hallamos

21 Alberola Romá, «No puedo sujetar la pluma de puro frío», pág. 69.

22 Armando Alberola Romá y Cayetano Mas Galvañ, «Vulnerabilidad y capacidad de resistencia frente al desastre en la España Mediterránea (siglos XVI-XVIII). Fuentes para su estudio», en Luis Alberto Arrioja Díaz Viruell y Armando Alberola Romá (eds.), Clima, desastres y convulsiones sociales en España e Hispanoamérica, siglos XVII-XIX, Alicante, Universidad de Alicante / El Colegio de Michoacán, 2016, págs. 41-60, pág. 57.

23 José Caso González, «Cartas inéditas de Jovellanos», Archivum: Revista de la Facultad de Filología, 13 (1963), págs. 292-310, pág. 310.

24 Carlos III a Bernardo Tanucci, Buen Retiro, 25/11/1760; en Carlos III. Cartas a Tanucci, pág. 167. 
el puerto cerrado y tan cerrado que ni los pájaros pasan. Habrá en él diez varas de nieve. Sabemos que hay muchos carruajes de la parte de allá. Muchos mulos han perecido. Yo envié dos hombres a visitar el paso, y volvieron medio helados con el correo Castañeda. Viéndome en este desierto, me fui esta mañana a pie a El Escorial, donde el padre prior me ha dado muy bien de comer. A la vuelta hallo muy malas noticias del puerto y todas combinan en que antes de tres días no podré pasar. Jura la consecuencia de mi diversión haber dejado a mis amigos de Madrid y estar en Guadarrama en una casa como un cubilete sin vidrios en las ventanas, con una infinidad de viajeros detenidos y sin qué comer. ${ }^{25}$

Por otro lado, la salud era un tema fundamental en las misivas privadas, pues informar de las dolencias personales o familiares era, como norma general, el primer comentario que se realizaba, así como interesarse por la del receptor. La presupuesta relación de la enfermedad con el clima hacía que muchas de las referencias a las condiciones atmosféricas aparezcan de la mano del estado de salud, como lo hace el erudito valenciano Gregorio Mayans en una carta enviada al doctor Luis Millera en marzo de 1741 hablando de su hinchazón de piernas: «puede que proceda de haberme mojado cuatro o seis días antes que empezase la hinchazón, un día que llovió. [...] Me inclino más a esta última causa, llegándose a ella el haber sido lluviosos estos días y muy húmedos» ${ }^{26}$. Incluso, el buen tiempo era recetado como remedio a algunas enfermedades, como le ocurrió a Benet de Burgués, teniente de la armada en Brest que padecía de una salud muy delicada, por lo que le fue concedido permiso para volver a España para restablecerse y «mudar de aires» en varias ocasiones ${ }^{27}$. Unos meses antes de su muerte informaba a su tío de una nueva dolencia, por la cual acabó siendo repatriado a España:

Querido tío y amigo: ayer me insinuaron los médicos que solicitara mi pasaporte para España, pues toda enfermedad de pecho se hace mortal en este país y la mía se va aumentando. [...] como todavía no hay nada perdido, y sólo con salir de este maldito temperamento me aseguran mi curación, como ha sucedido a otros, me parece que vuestra merced me creerá mejor. ${ }^{28}$

25 José Nicolás de Azara a Bernardo Iriarte, Guadarrama, 25/02/1801; en José Nicolás de AzAra Epistolario (1784-1804), pág. 949.

26 Gregorio Mayans a Luis Millera, Oliva, 25/03/1741; en Gregorio MaYans y Siscar, Epistolario I. Mayans y los médicos, pág. 445.

27 Antón Pelayo, La sociabilitat epistolar, pág. 45.

28 Benet de Burgués a Martí de Burgués, Navío de San Joaquín en Brest, 22/02/1800; en Antón PELAYO, La sociabilitat epistolar, pág. 176. 
No conviene olvidar que la influencia del clima en la agricultura era absoluta, por lo que la preocupación por la cosecha también era habitual en algunos corresponsales, que solían mostrar alegría cuando la lluvia mejoraba los campos: «de algunos días a esta parte tenemos un fresco de paraíso, fruto de varias tronadas que han regado estos alrededores y afianzado la gran cosecha que promete de olivas y uvas, que valen más que los papeles mojados de la Caja de Descuentos» ${ }^{29}$; o preocupación por la falta de agua: «tenemos tan buen tiempo que parece verano, y ya hace falta el agua para los campos, pero espero que Dios nos la envíe si nos conviene» ${ }^{30}$.

Cabe destacar que la subjetividad, característica evidente de esta fuente, puede afectar un mismo valor meteorológico, ya que algunos factores como la edad, el estado de salud, la hidratación o el tipo de actividad habitual pueden hacer variar el umbral de sensibilidad de una persona ${ }^{31}$. A pesar de ello, muchos de los comentarios sobre el temple que aparecen en la correspondencia no hablan de percepciones puramente individuales, sino que son el resultado de un consenso general acerca de la evolución del clima y de lo que serían los valores esperables de una estación y un lugar concreto ${ }^{32}$, como demuestran muchas referencias del monarca Carlos III sobre el tiempo de los Reales Sitios: «tenemos muy buen tiempo, y los días pasados ha hecho aquí un calor, que no hemos tenido igual, en los años que ha que estoy aquí, bien que sin comparación menor al que tienen en Madrid, que ha llegado a igualar al de Lima» ${ }^{33}$; $\mathrm{y}$, aunque son excepcionales, algunas referencias contienen información instrumental, como el deán Martí indicó a Gregorio Mayans en enero de $1729^{34}$. José Nicolás de Azara también hace uso del termómetro para dar cuenta del fuerte calor que hizo en Roma el verano de 1787: «Aquí nos asamos de calor. Los nacidos no han visto un verano tan terrible. Mi termómetro a la sombra ha llegado a 93 grados, y al sol en cinco minutos sube a $121 .{ }^{35} \mathrm{y}$, del mismo modo con los fuertes fríos del invierno de 1798: «Antes de ayer bajó el termómetro hasta 14 grados bajo la congelación, y ya te figurarás cuál habré estado yo, acostumbrado a no ver helar en treinta años. Quemo carros de leña sin poder

\footnotetext{
29 José Nicolás de Azara a Bernardo Iriarte, Barbuñales, 23/07/1800; en José Nicolás de AzARA, Epistolario (1784-1804), pág. 860.

30 Carlos III a Bernardo Tanucci, El Escorial, 19/10/1773, AGS, Estado, libro 344.

31 Alberola Romá y Mas Galvañ, «Vulnerabilidad y capacidad de resistencia», pág. 57.

32 Alberola Romá y Mas Galvañ, «Vulnerabilidad y capacidad de resistencia», pág. 58.

33 Carlos III a Bernardo Tanucci, San Ildefonso, 13/08/1771, AGS, Estado, libro 340.

34 Alberola Romá, «No puedo sujetar la pluma de puro frío», pág. 70.

35 José Nicolás de Azara al Conde de Aranda, Roma, 29/08/1787; en José Nicolás de AzAra Epistolario (1784-1804), pág. 74. Estas mediciones están realizadas en grados Fahrenheit y equivalen a 33, $8^{\circ} \mathrm{C}$ y $49,4^{\circ} \mathrm{C}$ respectivamente.
} 
entrar en calor» ${ }^{36}$. Que algunos de estos ilustrados efectúen mediciones con sus propios termómetros evidencia el creciente interés de estos personajes por el clima, además de reforzar el valor de sus propios comentarios con información objetiva, si bien no debemos olvidar que la incorporación de estas mediciones en la correspondencia es excepcional.

Por tanto, son las palabras que utilizan los corresponsales la única manera que tenemos de acercarnos a sus sensaciones sobre el clima. El léxico y las expresiones empleadas en las descripciones climáticas son el resultado de la percepción de las características meteorológicas y de su influencia en el entorno del emisor, que se vale del lenguaje para transmitir a su corresponsal las impresiones resultantes. Por tanto, estudiar el vocabulario utilizado en estas referencias será una parte fundamental para obtener información climática de calidad. El profesor Mas ya señaló la necesidad de elaborar un corpus lexicográfico sobre términos meteorológicos para comprender plenamente el lenguaje en el que se nos transmite la información en cuestión ${ }^{37}$. Además, la carta íntima de carácter familiar se suele valer de un lenguaje menos planificado, acercándonos a la lengua desde el ámbito privado de quienes intercambian estas misivas, permitiéndonos conocer sus usos lingüísticos y sociales, porque la naturaleza del contenido y la identidad del emisor y el receptor desempeñan un papel destacado en la variación lingüística ${ }^{38}$. De ahí que sea imprescindible realizar un estudio léxico individualizado que intente objetivar, en la medida de lo posible, la subjetividad presente en la correspondencia.

En este estudio léxico ha sido esencial la identificación y la clasificación del vocabulario utilizado en las referencias climáticas contenidas en cada uno de los epistolarios vaciados. En este proceso, nos hemos percatado de una singularidad que caracteriza la correspondencia de José Nicolás de Azara, quien, como bien analiza Gimeno Puyol, mezclaba en sus frases el regusto de lo coloquial y la pericia literaria, consiguiendo el equilibrio entre la elegancia clásica y la familiar ${ }^{39}$. Así, el diplomático hará uso de figuras literarias que relacionan diferentes elementos de la naturaleza con los acontecimientos políticos, sobre todo en sus últimos años en París como embajador. En un momento especialmente delicado en las relaciones hispano-francesas, diferentes asuntos provocaron una disminución de la confianza que la Secretaría de Estado española

36 José Nicolás de Azara a Bernardo Iriarte, París, 28/12/1798; en José Nicolás de AzAra Epistolario (1784-1804), pág. 723. Esta vez, Azara mide la temperatura en grados Celsius.

37 Mas GaLVañ, «El clima en la correspondencia de Carlos III» pág. 26.

38 Abad Merino, «'Muy señor mío, dueño y amigo'», pág. 3.

39 María Dolores Gimeno Puyol, «Estudio Preliminar», en José Nicolás de Azara, Epistolario (17841804), pág. CLXXVII. 
había depositado en él, acusado de provocar actitudes desfavorables de Bonaparte $^{40}$. En este contexto, Azara hará uso del vocabulario atmosférico como metáfora de la situación política entre ambos países: "Yo ignoro el tiempo que hace por la Malmaison ${ }^{41}$, pero infiero que será muy tempestuoso y que podrá descargar en rayos y granizo. El primero a quien mojarán será a mí, pero a bien que tengo previsto el aguacero armándome de una doble capa a prueba» ${ }^{42}$; o como comparación para mostrar su preocupación por la situación política que se estaba viviendo: «Esta embajada me parece al caminante sorprendido al raso de una horrible tempestad, y que no ve alrededor sino oscuridad, rayos y granizo» ${ }^{43}$. Aunque estas referencias de carácter literario no pueden incluirse en nuestro estudio climático porque es evidente que no hacen alusión a las condiciones meteorológicas, sí ponen de relieve el carácter peyorativo que se dan a los fenómenos mencionados (tempestades, rayos, grandes nubes, aguacero y granizo), pues Azara los usa para relacionarlos con las dificultades políticas que acontecían.

La percepción del autor influye en la ambigüedad de los términos utilizados a la hora de describir la intensidad de un fenómeno, de ahí el interés en comprender el sentido de las referencias al tiempo a través del estudio léxico. En este contexto, se ha optado por adoptar el estudio del vocabulario propuesto por el análisis de contenido, metodología que responde al problema principal que presenta la correspondencia, la subjetividad del léxico. Se ha definido esta metodología como «una técnica de investigación que identifica y describe de una manera objetiva y sistemática las propiedades linguiísticas de un texto con la finalidad de obtener conclusiones sobre las propiedades no lingüísticas de las personas y los agregados sociales.» ${ }^{44}$. Es decir, el análisis de contenido tiene como objetivo sustituir las dimensiones subjetivas de un documento a partir de un procedimiento estandarizado que convierta en datos objetivos los contenidos de la fuente.

Esta técnica ya ha sido utilizada anteriormente en estudios climáticos que, aunque minoritarios, han conseguido resultados interesantes. Destacan como

\footnotetext{
40 Gimeno Puyol, «Estudio Preliminar», en José Nicolás de Azara, Epistolario (1784-1804), pág. LXXXIX.

41 El Castillo de Malmaison fue la residencia de Napoleón Bonaparte entre 1800 y 1804, hasta la proclamación del Imperio y su traslado a la capital.

42 José Nicolás de Azara a Manuel Godoy, París, 16/08/1801; en José Nicolás de AzAra Epistolario (1784-1804), pág. 980.

43 José Nicolás de Azara a Bernardo Iriarte, París, 08/09/1803; en José Nicolás de AzAra Epistolario (1784-1804), pág. 1057.

44 Renate Mayntz; Kurt Holm; Peter HüBner, Introducción a los métodos de la sociología empírica, Madrid, Alianza Editorial, 1980.
} 
pioneros Moodie y Catchpole, quienes en 1975 analizaron los diarios meteorológicos de la Hudson's Bay Company empleando como metodología el análisis de contenido $^{45}$; también William Baron lo utilizó en 1982 para reconstruir la temperatura del siglo XVIII en Boston ${ }^{46}$. Más recientemente, esta metodología ha sido empleada de nuevo en estos términos por algunos autores como María del Rosario Prieto ${ }^{47}$; Domínguez Castro, García Herrera y Vaquero ${ }^{48}$; o Gil Guirado, quien, en su tesis doctoral, analizó a partir de esta técnica, entre otras, el clima de las cuencas de los ríos Segura (España) y Mendoza (Argentina) ${ }^{49}$. Estos estudios corroboran las posibilidades de esta metodología por sí misma o combinada con otras técnicas ${ }^{50}$.

Moodie y Catchpole señalaron que las ventajas del análisis de contenido se basan en que permite medir las percepciones de los observadores del pasado con mucha más precisión que los clásicos métodos de análisis histórico. Así, el análisis de contenido trata de examinar la frecuencia terminológica y la intensidad de los conceptos clave, definidos en unidades de información o significación, que pueden ser tanto palabras, como partes de frases, frases enteras, etc. El objetivo es sintetizar el material estudiado, reduciéndolo a categorías analíticas que lo hacen manejable para realizar una investigación ${ }^{51}$.

En estos trabajos la validez del método para su aplicación en la historia ambiental ha quedado demostrada, pero en todo caso, son las características de

45 D. Wayne Moodie y Alan Catchpole, Environmental Data from Historical Documents by Content Analysis: Frezze-Up and Break-Up of Estuaries on Hudson Bay 1714-1871, Manitoba, Manitoba Geographical Studies, Atmospheric Enviroment Service, Department of Environment, 1975.

46 William BARON, «The reconstruction of eighteenth century temperature records through the use of content analysis», Climatic Change, 4 (1982), págs. 385-398.

47 Ejemplos de sus trabajos utilizando esta técnica son: María del Rosario Prieto, David Gallego, Ricardo García-Herrera y Natalia Calvo, «Deriving wind force terms from nautical reports through content analysis. The Spanish and French cases», Climatic Change, 73 (2005), págs. 37-55; María del Rosario Prieto, Pablo Eugenio Villagra, Nerina Belén Lana; Elena María Abraham, «Utilización de documentos históricos en la reconstrucción de la vegetación de la Llanura de la Travesía (Argentina) a principios del siglo XIX», Revista Chilena de Historia Natural, 76 (2003), págs. 613- 622.

48 Fernando Domínguez-Castro; Ricardo García-Herrera; José M. Vaquero, «An early weather diary from Iberia (Lisbon, 1631-1632)», Weather, 70, 1 (2015), págs. 20-24.

49 Salvador Gil Guirado, Reconstrucción climática histórica y análisis evolutivo de la vulnerabilidad y adaptación a las sequías e inundaciones en la cuenca del Segura (España) y en la cuenca del río Mendoza (Argentina), Tesis doctoral dirigida por José María Gómez Espín y María del Rosario Prieto, Murcia, Universidad de Murcia, 2013.

50 Salvador GiL Guirado, «El tiempo entre palabras: nuevas fuentes metodológicas para el estudio del clima a partir de fuentes históricas», en Armando Alberola Romá (coord.), Riesgo, desastre y miedo en la península ibérica y México durante la Edad Moderna, Servicio de Publicaciones de la Universidad de Alicante, 2017, págs. 15-45. Una posterior versión en inglés de esta contribución en Salvador GIL-Guirado, Juan José Gómez-Navarro y Juan Pedro Montávez, «The weather behind the words. New methodologies for integrated hydrometeorological reconstruction through documentary sources», Clim. Past. Discuss. (2019), 29 págs.

${ }^{51}$ Gil Guirado, Reconstrucción climática histórica, págs. 416-417. 
cada fuente las que determinarán si este método es o no útil para la misma. Si bien la propia objetivación de la información es un proceso complejo en el que no vamos a ahondar en estas páginas, el estudio léxico que se ha realizado en la correspondencia siguiendo las pautas propuestas por el análisis de contenido sí nos ha aportado interesantes perspectivas sobre el vocabulario utilizado, por lo que, presentaremos a continuación su aplicación en el epistolario de Carlos III y Bernardo Tanucci ${ }^{52}$.

Caso de estudio: la correspondencia de Carlos III y Bernardo Tanucci (1759-1782)

Como hemos comentado anteriormente, el profesor Mas Galvañ se percató de la singularidad de la correspondencia del monarca Carlos III a través del estudio de las misivas que le enviaba a su hermano Felipe de Parma entre 1759 y 1765; es decir, desde la llegada del primero a España para comenzar su reinado hasta la muerte del titular del ducado de Parma. Durante todo este intercambio epistolar semanal, el monarca acostumbraba a describir las condiciones climáticas del Real Sitio en el que se encontraba debido a su afición cinegética. Además, también comprobó que existía una segunda fuente simultánea y parcialmente publicada que son las cartas que Carlos III envió a Bernardo Tanucci desde 1759 hasta 1783, con la muerte del ministro italiano, de las que Maximiliano Barrio publicó los primeros años, concretamente hasta 1763. En ellas, pudo confirmar que estas referencias al tiempo meteorológico no estaban exclusivamente dirigidas a su hermano, sino que también existían en este segundo epistolario, por lo que, la continuidad lógica era ampliar el estudio climático y analizar el resto de las cartas, que sumaban 23 años de misivas semanales. Es decir, su singularidad residía en que se trataba de una fuente muy extensa y regular, al igual que perfectamente fechable, cumpliendo de entrada dos de las características básicas requeridas anteriormente mencionadas.

La correspondencia de don Carlos con Tanucci comienza con la llegada del monarca a España para comenzar su reinado tras la muerte de Fernando VI,

52 Este estudio léxico proviene de la doble aplicación metodológica realizada en mi Trabajo de Fin de Máster. En él, se analizaron las referencias climáticas contenidas en la correspondencia de Carlos III a partir, por un lado, del método de Mariano BARRIEndos («La climatología histórica en el marco de la antigua monarquía hispana», Scripta Nova. Revista electrónica de Geografía y Ciencias Sociales, 53 1999) y, por otro, el análisis de contenido, aplicado a partir de los trabajos de Salvador Gil Guirado ya citados en las notas 49 y 50. En el presente texto, se pretende incidir solamente en la importancia del análisis léxico derivado del empleo del análisis de contenido, mientras que los datos resultantes de la aplicación de ambos métodos se publicarán en posteriores trabajos. 
con lo cual tuvo que renunciar a sus dominios italianos. Por ello, se nombró rey de Nápoles a su tercer hijo, Fernando, cuya minoría de edad forzó el establecimiento de un gobierno de regencia del que Bernardo Tanucci fue su principal miembro y confidente. Así comienza un intercambio epistolar que trascenderá a esta regencia, pues continuó tras la mayoría de edad de Fernando IV e, incluso, tras la destitución de Tanucci del gobierno napolitano en 1776, cosa que demuestra la afectuosa relación entre ambos. Todas estas cartas se recogieron en 38 volúmenes enviados al Archivo General de Simancas, lugar en el que actualmente se encuentran (Estado, libros 318 a 355) y que han sido consultadas en su totalidad para realizar este trabajo ${ }^{53}$. El estudio de Maximiliano Barrio ya recalcó la importancia y el interés que tenía esta correspondencia en múltiples ámbitos de la historia española e internacional ${ }^{54}$, aunque su extensión y la variedad de los temas que en ella se abordan no nos permite abarcarlos completamente en estas páginas. Buen ejemplo de la complejidad que adquieren es el considerable cambio en la propia extensión de las cartas, porque mientras que Barrio estableció una media de 8 páginas de extensión para los primeros años de dicha correspondencia, durante los años centrales esta media aumentó, concretamente hasta el año 1776, cuando el ministro italiano quedó apartado del gobierno. A partir de este momento, la extensión de las cartas disminuyó a unas dos páginas y media por carta hasta el final de este intercambio epistolar. Por tanto, la gran cantidad de los asuntos políticos que se tratan durante estos veintitrés años merecen un estudio específico.

Sin embargo, las noticias políticas no lo son todo en esta correspondencia, sino que se entremezclan con las de ámbito familiar y privado que, además, sí son constantes en todas y cada una de las cartas. Las referencias al estado de salud de la familia real, tanto la española como la napolitana, eran persistentes y exhaustivas. Al comienzo de la carta, don Carlos solía dar las gracias a Tanucci por la información sobre sus hijos residentes en Nápoles, Fernando y Felipe, agradeciendo cuando se encontraban bien y pidiendo su pronta recuperación cuando tenían la más mínima calentura. Al final de la carta, era el monarca el que informaba sobre el estado de salud de la parte española de la familia, dando un parte riguroso de toda clase de dolencias, así como el seguimiento de los embarazos de la princesa e, incluso, sobre los dientes que le iban saliendo a cada uno de sus nietos.

53 Estos volúmenes contienen, por tanto, todo el epistolario conservado, que abarca desde octubre de 1759 hasta diciembre de 1782. Solamente encontramos dos pérdidas en esta serie, que son el libro que contiene las cartas de la primera mitad del año 1762 y las de enero a abril de 1783, momento en el que finaliza el epistolario por la muerte de Tanucci.

54 Maximiliano Barrio, «Introducción», Carlos III. Cartas a Tanucci. Madrid, 1988, pág. 1. 
También solía dedicar unas líneas al comienzo de la carta para mostrar interés por las listas de las cazas de su hijo Fernando y hablar sobre las suyas propias, que se adjuntaban cada semana. E, incluso, instaba al ministro italiano a que obligase a su hijo a practicarla, pues la consideraba «la diversión más propia para un soberano ${ }^{55}$. La importancia del ejercicio cinegético en la vida diaria del monarca queda patente en la reiteración de este tema en su correspondencia, y no sólo con Bernardo Tanucci, sino también con su hermano Felipe de Parma. La preocupación del monarca por la caza viene dada, además de su pasión por ella, por la creencia de que esta práctica prevenía la neurastenia depresiva que muchos miembros de su familia sufrieron, como su padre, su hermanastro Fernando o su hijo Felipe Pascual ${ }^{56}$. Ejemplos de ello encontramos en la correspondencia con Tanucci, como las palabras que dedica a esta práctica poco después de la muerte de su esposa María Amalia:

Te aseguro que también deseo empezar a ver notas de cazas suyas [de su hijo Fernando], por ser el divertimento más inocente, y que quita muchos pensamientos y ocasiones como bien sabes que hablamos los dos sobre ello, y lo cual puedo yo decir mejor que nadie lo útil que es, pues sé lo que me ha sucedido y de lo cual doy mil gracias a Dios conociendo el gran beneficio que me ha hecho ${ }^{57}$.

Es en este contexto, centrado en las noticias de carácter privado y normalmente relacionándolo con estos dos aspectos, la salud y, sobre todo, la caza, cuando el monarca dedica unas líneas a hablar del tiempo reinante. Además, como hemos indicado anteriormente la singularidad de la fuente reside en que no se limita a indicar los acontecimientos meteorológicos extraordinarios o cuándo mudaba el tiempo, sino que Carlos III informaba a Tanucci del tiempo regularmente. Si hablamos de números, el volumen de cartas asciende a 1.191, de las cuales contienen referencias climáticas 1.003, es decir, el $84 \%$ del total.

Excepto 1759, cuando en que comienza el intercambio epistolar, y 1762, debido a la pérdida de uno de los dos tomos que conforman la correspondencia de ese año, todos los demás hubo un intercambio mínimo de 52 cartas, a razón de una por semana, más algunas excepcionales ante algún acontecimiento importante, que pueden aumentar este volumen anual a 54. En estas últimas, como norma general, no hay referencias climáticas pues sólo infor-

55 Carlos III a Bernardo Tanucci, El Escorial, 22/11/1763, AGS, Estado, libro 325.

56 Roberto Fernández, Carlos III. Un monarca reformista, Barcelona, Espasa, 2016, pág. 249.

57 Carlos III a Bernardo Tanucci, Buen Retiro, 21/10/1760, en Carlos III. Cartas a Tanucci (17591763),pág. 155. 
man del hecho especial en cuestión. Dejando de lado estas excepciones, el año con menor número de referencias climáticas es 1775 , con un total de 36 , de las 54 cartas enviadas, cosa que supone el $67 \%$, que sigue siendo una cifra considerable. Los años con mayor número de referencias climáticas son los seis últimos — todos con más de 50 anuales, rozando así el 100\%-, que corresponden exactamente con aquellos en los que Tanucci fue apartado del poder. En ellos, como se ha indicado anteriormente, hay una reducción considerable del número de páginas que integran cada carta, por lo que no se puede relacionar la longitud de la correspondencia con una mayor cantidad de referencias climáticas. Sin embargo, una de las razones por las que existe este aumento de referencias en estos últimos años podría responder al descenso de los temas de índole gubernamental y el aumento de los privados. A partir de 1777, las misivas se centran más en las cuestiones sobre la familia real napolitana y española y en las cuestiones cinegéticas, pues en estos últimos años de intercambio epistolar, el monarca describe las piezas cazadas en la propia carta y posteriormente indica la influencia que el clima había tenido esa semana en relación a esta actividad o en las cosechas. Cabe destacar que una primera hipótesis relacionaría la falta de tiempo del monarca para escribir, a la que en ocasiones alude explícitamente, con la ausencia en esas cartas de referencia climática, cosa que significaría que don Carlos consideraría esta información como secundaria. Sin embargo, de las misivas contabilizadas en las que se indica explícitamente la carencia de tiempo, más del $70 \%$ sí contienen alusiones al clima, por lo que no existe una relación directa entre estas dos premisas.

Tras extraer todas las referencias climáticas contenidas en la correspondencia, el siguiente paso será la realización del estudio léxico. Para llevarlo a cabo, se ha utilizado el análisis de contenido a partir de los trabajos ya mencionados de Gil Guirado. La aplicación de esta primera parte del método ha ayudado en la clasificación y comprensión del vocabulario utilizado. El primer paso descrito es categorizar la semántica de manera lógica diferenciando los fenómenos que describe según a qué hagan referencia ${ }^{58}$. Se ha optado por simplificar las categorías a cuatro, por un lado, precipitaciones y sequías; y por otro, frío y calor. Esta selección se ha realizado teniendo en cuenta las características de la fuente, pues Carlos III se basa en la ausencia o la presencia de lluvias para describir las condiciones atmosféricas del lugar y el momento en el que se encuentra, mientras que la temperatura será una característica menos frecuente, descrita normalmente, por ser excesivamente fría o calurosa, por no

58 Gil Guirado, Reconstrucción climática, pág. 419. 
ser propia de la estación en la que el monarca se encuentre o por ser diferente a lo esperable en el Real Sitio en el que se halle —v. gr. «estos días ha hecho bastante calor para el que suele hacer en este Sitio» ${ }^{59}$ - Es interesante destacar la itinerancia de la corte, pues el monarca se va desplazando por los diferentes Reales Sitios ${ }^{60}$ y cada uno de ellos tienen unas características climáticas concretas; es decir, que Carlos III describe el clima en cada momento sabiendo qué es lo que se espera en cada lugar. Sin embargo, las diferencias entre algunos son importantes, destacando sobre todo la Granja de San Ildefonso, donde el monarca iba a pasar el periodo estival debido al descenso de temperaturas con respecto a la capital. El propio monarca se percata de ello tras los viajes de ida y vuelta al Sitio segoviano, como comenta el 12 de octubre de 1772, cuando, tras su vuelta de San Ildefonso al Escorial: «hemos hallado un clima totalmente diverso, pues en San Ildefonso hacía casi frío y había algo de nieve en lo alto de la Montaña, y aquí hace casi calor y hay mucho polvo» ${ }^{61}$. Es por ello que, sobre todo en cuanto a las temperaturas, es importante tener en cuenta el Real Sitio en el que se halle a la hora de realizar interpretaciones, si bien cabe destacar que la itinerancia es la misma a lo largo de los años.

También encontramos en las cartas del monarca alusiones al tiempo de Nápoles que son el resultado de repetir la información que el ministro italiano le da, al igual que ocurre con las referencias al tiempo de Parma que el Mas Galvañ encontró en las misivas a su hermano don Felipe ${ }^{62}$. La imposibilidad de recuperar toda la serie de misivas que Tanucci envió a don Carlos convierten estas alusiones en la única fuente para conocer la información climática que el ministro le daba al rey. Esta segunda serie sobre el clima napolitano es menos potente que la propia del clima en los Reales Sitios españoles, pero igualmente importante, demostrando el interés que el monarca tenía por el tiempo que hacía en Nápoles y la influencia que adquiría en la vida de los familiares que permanecían en Italia. A pesar de que no se va a incidir en esta segunda serie, el vocabulario utilizado en las referencias al clima napolitano sí ha formado parte de este estudio léxico.

Después de establecer las cuatro categorías, se deben identificar todas las expresiones que se emplean para describir cada una de ellas y, tras comprobar las diferentes maneras en las que el sujeto expresa una misma realidad, crear las denominadas "unidades de registro", que contienen las diferentes

59 Carlos III a Bernardo Tanucci, San Ildefonso, 10/08/1773, AGS, Estado, libro 344.

60 Para conocer el itinerario concreto, consultar Cayetano MAS GALVAÑ, «El clima en la correspondencia de Carlos III», pág. 28.

${ }_{61}$ Carlos III a Bernardo Tanucci, El Escorial, 12/10/1772, AGS, Estado, libro 342.

62 Mas Galvañ, «El clima en la correspondencia de Carlos III», págs. 48-53. 
locuciones utilizadas para describir el mismo fenómeno ${ }^{63}$. Cabe destacar en esta fuente concreta que no existen muchos descriptores o términos concretos diferentes, sino que son los adverbios o intensificadores que los acompañan los que varían su significado y determinan, en muchos casos, estas unidades de registro. Todas las expresiones encontradas se agrupan, pues muchas de ellas son sinónimos o su significado es el mismo. Para intentar identificar el sentido exacto de los términos utilizados se ha consultado el Diccionario de Autoridades ${ }^{64}$. El resultado de la consulta, tal y como se ha observado en otros estudios, es que no existen cambios significativos en el uso del lenguaje para describir anomalías climáticas tras el paso del tiempo ${ }^{65}$. Este proceso supuso una reducción del número de unidades de registro en todas las categorías. Se encontraron 23 expresiones diferentes en la categoría de sequía que han quedado reducidas a 5; las 26 referentes a precipitaciones se han reducido a 6; otras 6 son las unidades de registro que corresponden a las 14 expresiones encontradas que hacían referencia al calor; y, finalmente, son otras 7 unidades de registro designadas para el frío de las 23 iniciales.

Estas clasificaciones han ayudado a esclarecer enormemente el vocabulario utilizado por el monarca, que ha sido ordenado de menor a mayor intensidad en cada categoría, lo que ha suscitado una serie de reflexiones. En cuanto a la categoría referente a la ausencia de precipitación, cabe destacar que no existe ningún término específico empleado por don Carlos que describa la sequía, sino que es frecuente que recurra a expresiones explícitas sobre la falta de agua $-v$. gr. «ya se desea el agua, la que espero que Él nos envíe si conviene»; «ya hace falta el agua para los campos, pero espero que Dios nos la envíe si nos conviene»; «tan seco que hace falta el agua, pero espero en Dios que nos la envíe presto por su inmensa piedad»-. Todas estas expresiones se han clasificado como el grado más alto de esta categoría, pues su significado es el mismo. Así, será la cantidad de reiteraciones sobre la falta de agua las que podrían determinar el grado y la prolongación de dicha sequía.

Los términos más utilizados a lo largo de toda la correspondencia son los que describen un tiempo sin precipitación y generalmente agradable. En este caso, los más utilizados son «hermoso» y «bueno», con sus correspondientes aumentativos, que aparecen 309 y 302 veces, respectivamente. En menor número de ocasiones encontramos el término «bello», concretamente 36 veces;

63 GIL Guirado, Reconstrucción climática, 419.

64 Real Academia Española: Diccionario de la lengua castellana, en que se explica el verdadero sentido de las voces, su naturaleza y calidad, con las phrases o modos de hablar, los proverbios o refranes, y otras cosas convenientes al uso de la lengua, 1726-1739, Disponible en red.

65 Gil Guirado, Reconstrucción climática, pág. 422. 
«admirable», en 5 ocasiones; $\mathrm{y}$, «favorable» $\mathrm{y}$ «sereno», que aparecen dos veces cada una; y «luminoso», que sólo aparece en una ocasión. Todos estos términos vienen a describirnos el mismo suceso, es decir, la ausencia de precipitación. Para conocer la equivalencia de significado de estos términos ha sido importante la existencia del epistolario de Carlos III con su hermano Felipe de Parma, pues, en ocasiones, el monarca no usa el mismo término que en las cartas enviadas en las mismas fechas a Tanucci. Así, encontramos diferencias léxicas que describen el mismo acontecimiento: el día 30 de noviembre de 1762, en el que D. Carlos le dijo a su hermano que hacía un tiempo «muy hermoso» ${ }^{66}$ y a Tanucci que lo hacía «luminoso» ${ }^{67}$; «hermosísimo»/«buen tiempo» ${ }^{68}$; «muy hermoso»/ $/$ admirable» ${ }^{69}$. En este caso, los aumentativos y adverbios que acompañan a estos descriptores no condicionan especialmente el significado, pues no es ponderable en estos casos la diferencia entre un tiempo hermoso y uno hermosísimo, por lo que se ha optado por ubicarlos de igual forma en la misma unidad de registro. Sólo encontramos un pronombre que altera el significado de manera relevante en este estudio, cuando se usa la expresión demasiado buen tiempo para hacer referencia a la reiteración prolongada de un tiempo ausente de precipitaciones, mostrando así su queja por ello. Por último, existen algunos términos y expresiones referentes a la vuelta a un tiempo estable tras un tiempo lluvioso: «compuesto», «mejor», «se nos quiere asegurar al bueno» y «más bueno que malo» que son utilizadas por el monarca en este orden de frecuencia.

En cuanto a las precipitaciones, en primer lugar, encontramos los términos: «vario» (utilizado 52 veces), «revuelto» (34 veces) «inconstante» (5 veces), «embrollado» (2 veces), que hacen referencia a un tiempo variable o inestable. Estos suelen ir acompañados por una descripción más detallada que suele indicar si ha llovido, en el caso de que lo haya hecho, o si este tiempo se ha intercalado con otros días más despejados. En este caso, no serán los descriptores utilizados los que marquen las unidades de registro, sino que lo harán los intensificadores, que son los que varían el significado de la referencia climática. Por tanto, en la misma unidad encontramos referencias a diferentes fenómenos atmosféricos como la lluvia o la nieve indistintamente, a pesar de que en los siguientes ejemplos se haga referencia solo a la primera. En esta clasificación

66 En estas comparativas, el primer término lo encontramos en las cartas a Felipe de Parma mientras que el segundo es el utilizado en la correspondencia con Tanucci. Para consultar las citas del epistolario de Carlos III con su hermano D. Felipe es preciso ver el ya citado trabajo del profesor Mas.

67 Carlos III a Bernardo Tanucci, Buen Retiro, 30/11/1762, AGS, Estado, libro 324.

68 Carlos III a Bernardo Tanucci, Buen Retiro, 19/02/1760 en Carlos III. Cartas a Tanucci (17591763), pág. 69.

69 Carlos III a Bernardo Tanucci, Aranjuez, 25/04/1763 AGS, Estado, libro 323. 
encontramos precipitaciones poco intensas: «ha llovido un poco», «ligeras tempestades», «ha llovido de cuando en cuando», y «han sido muy pocas las gotas que han caído»; otras de gran intensidad: "ha llovido como en lo fuerte del invierno», «llover intempestivamente», «llover fuertemente», tiempos «horrorosos» o tiempos «horribles»; otras en las que las precipitaciones son abundantes, pero menores a las anteriores: «malos tiempos», «llover mucho»; y, por último, aquellas en las que no encontramos intensificadores, o estos tienen un significado positivo, vinculado normalmente a las cosechas: «llover», «buena agua», «llovido muy bien», «buena tempestad». Por último, también aparecen en esta correspondencia referencias a inundaciones provocadas por lluvias excesivas que, aunque muy escasas, suponen el grado más alto en esta categoría.

Dentro de las referencias térmicas, se ha diferenciado, como se ha dicho, el calor del frío. En cuanto al primero de ellos cabe destacar que la palabra calor es el único descriptor utilizado, por lo que, de nuevo, serán los intensificadores los que determinarán su grado. Así, encontramos referencias a calores extremos: «un calor que no hemos tenido igual en los años que ha que estoy aquí», «calor insufrible», «calor grandísimo», entre otras descripciones que posteriormente veremos; algunas en las que el descriptor se encuentra solo, como «calor» o «caliente», o que, de nuevo, tienen un significado positivo, como «buen calor»; y otras con intensificadores más moderados como «algo de calor», «calor muy sufrible», «calor muy moderado» o «no muy caliente». También cabe destacar la expresión «casi calor», que suele ser utilizada en aquellos momentos en los que hay una temperatura agradable cuando no es lo esperable de la estación en la que el monarca se encuentra: «tenemos un tiempo hermoso y tanto que estos días ha hecho casi calor» ${ }^{70}$.

En cambio, Carlos III sí utiliza más descriptores a la hora de hablar del frío, pues encontramos «templado», «fresco», y «frío», acompañados, de nuevo, con sus intensificadores. Las expresiones clasificadas con una menor intensidad son «ha refrescado el tiempo» y «templado», que han sido consideradas sinónimos gracias a las definiciones del Diccionario de Autoridades; a continuación, encontramos el descriptor «fresco», que suele ir acompañado de intensificadores, tales como «bastante», «más que», «demasiado» o «muy fresco», que conforman una nueva unidad de registro junto con la expresión «casi frío», que se ha considerado equivalente en significado; también cabe destacar las expresiones «tan fresco que se puede decir que hace frío», «tanto fresco que estamos vestidos de paño» o «tan fresco que ha sido preciso ponerse más ropa», que han sido categorizados junto al descriptor «frío», sin ningún intensificador, mien-

${ }_{70}$ Carlos III a Bernardo Tanucci, El Pardo, 11/03/1766, AGS, Estado, libro 330. 
tras que en otra unidad de registro encontramos «frío sensible», «frío formal», «bastante» y «bien frío». Posteriormente encontramos aquellas expresiones que hacen referencia a un frío intenso como «tiempo robusto», "gran frío» o «mucho frío», y, además, se ha incorporado en esta unidad la expresión «helar mucho» o «fuertemente», pues la existencia de heladas indica que las temperaturas son considerablemente bajas. Por último, especial atención merecen las expresiones calificadas como la unidad de registro más alta en esta categoría, pues, son muy descriptivas, destacando por su reiteración «invierno rigurosísimo» o «hace frío como en lo fuerte del invierno», empleada sobre todo en primavera para indicar un fuerte descenso de temperaturas.

Cabe destacar la existencia de expresiones que hacen referencia a las estaciones, destacando entre ellas las más utilizadas, «tiempo de primavera»y «tiempo de otoño», que han sido clasificadas gracias, de nuevo, a la correlación entre los epistolarios con Tanucci y Felipe de Parma. También es importante tener en cuenta la ausencia de referencias climáticas cuando se dispone de documentación. En otros estudios climáticos que utilizan otras fuentes, queda claro que la carencia de información supone la normalidad del clima, pues es más usual que se informe de lo extraordinario ${ }^{71}$. Esta fuente tiene la particularidad de que también comunica cuándo el clima se enmarca en lo esperable, pero se parte de la hipótesis de que en el caso de que hubiese un suceso fuera de la normalidad o un cambio considerable en la meteorología don Carlos lo advertiría en su correspondencia debido a la preocupación que tiene por las cuestiones climáticas. Por ello, la ausencia de datos en este caso supone un dato en sí mismo, concretamente que el tiempo no se desmarca de los umbrales esperables.

Atendiendo a este estudio léxico, podemos deducir que la información meteorológica contenida en todas las referencias encontradas en este epistolario se transmite a través de un vocabulario conciso, repleto de fórmulas que se repiten para representar una realidad concreta. Es decir, el monarca suele usar las mismas expresiones para hablar del tiempo, que son modificadas a partir de adjetivos o adverbios que varían su significado, aumentando o disminuyendo el fenómeno descrito. Si bien los protagonistas de otros epistolarios analizados, como José Nicolás de Azara, utilizan un lenguaje más elaborado en el que pueden tener cabida referencias más gráficas al tiempo meteorológico, Carlos III se vale de expresiones más directas y recurrentes que facilitan la labor tanto de

71 Algunos de ellos son: GIL GuIRAdo, Reconstrucción climática histórica, pág. 423; Mariano BaRRIENDos, «El clima histórico de Catalunya (siglos XIV-XIX). Fuentes, métodos y primeros resultados» Revista de geografía, 30-31 (1996-97), pág. 73; BARON, «The reconstruction of eighteenth century», pág. 389. 
comprensión del vocabulario, como de sinonimia y codificación. Es importante aclarar que todas estas alusiones al clima no tienen un carácter científico y, además, suelen vincularse a Dios, pidiendo unas condiciones climáticas concretas o dándole gracias por ellas, normalmente asociado con las necesidades de la cosecha. Y además suele relacionar estas descripciones sobre el tiempo con su actividad preferida, la caza. La reiteración de este tema en este epistolario refleja el interés del monarca en este tipo de cuestiones, y también de Bernardo Tanucci, pues a pesar de que no conservamos las cartas que el ministro enviaba al rey, las cartas escritas por don Carlos repiten en muchas ocasiones la información meteorológica de las que su interlocutor le informaba.

\section{Conclusiones}

Entender el sentido de la información meteorológica es una parte básica en el estudio de las referencias climáticas contenidas en las cartas, pues como hemos estado reiterando, estamos ante una fuente subjetiva que necesita de una metodología que haga que la información contenida en ella sea válida para este tipo de estudios. El análisis del léxico climático será, por tanto, un paso fundamental que supone no solo entender el significado del lenguaje utilizado, sino en qué contexto suelen aparecer estas referencias, cosa que también puede aportar nuevas perspectivas del uso social de estas alusiones al tiempo atmosférico.

En este estudio léxico, el análisis de contenido ha tenido un papel importante para la creación de categorías y la clasificación del vocabulario o expresiones utilizadas, generando unidades de significado a través de la sinonimia. La aplicación de esta metodología ha facilitado la comprensión del lenguaje empleado por el monarca, pues la cantidad de referencias climáticas contenidas en la fuente dificultaba el análisis individualizado de cada una de ellas. Sin embargo, para comprobar realmente la eficacia de esta metodología en este tipo de fuente es fundamental su aplicación en otros epistolarios que contengan este tipo de referencias, cosa que también ayudaría a precisar el desarrollo metodológico. A pesar de que es un proceso lento debido a la gran cantidad de documentación existente y a la necesidad de trabajar fuentes continuas que nos aporten series de amplio recorrido, la validez y la singularidad de la correspondencia como fuente para el estudio climático han quedado demostradas. La información obtenida en este tipo de fuente debe continuar trabajándose, pues reflejan el impacto directo del clima en la sociedad y su capacidad de resiliencia. Por tanto, es necesario continuar incorporando epistolarios que aporten nuevas perspectivas, siempre sin olvidar que resulta fundamental comparar los 
resultados obtenidos con otros tipos de fuente. Atender al léxico utilizado será un primer paso fundamental, sobre todo en los epistolarios, pues la comprensión del vocabulario y su análisis va a acercarnos a la percepción del clima de su autor para posteriormente contrastar los resultados, enriqueciéndolos y completándolos. 